\title{
Neopterin: A Promising Candidate Biomarker for Severe COVID-19
}

This article was published in the following Dove Press journal:

Journal of Inflammation Research

\author{
Wasihun Hailemichael (D) \\ Mulugeta Kiros (iD ${ }^{2}$ \\ Yibeltal Akelew (iD ${ }^{3}$ \\ Sisay Getu (iD) 4 \\ Henok Andualem (D) \\ 'Immunology and Molecular Biology, \\ Medical Laboratory Science, College of \\ Health Sciences, Debre Tabor University, \\ Debre Tabor, Ethiopia; ${ }^{2}$ Medical \\ Microbiology, Medical Laboratory \\ Science, College of Health Sciences, \\ Debre Tabor University, Debre Tabor, \\ Ethiopia; ${ }^{3}$ Immunology and Molecular \\ Biology, Medical Laboratory Sciences, \\ College of Health Sciences, Debre \\ Markos University, Debre Markos, \\ Ethiopia; ${ }^{4}$ Hematology and Immuno- \\ Hematology, Medical Laboratory Science, \\ College of Health Sciences, Debre Tabor \\ University, Debre Tabor, Ethiopia
}

Correspondence: Wasihun Hailemichael Immunology and Molecular Biology, Medical Laboratory Science, College of Health Sciences, Debre Tabor University, Debre Tabor, Ethiopia

Tel +25I 946III4I4

Email wasihunh383@gmail.com

\begin{abstract}
Severe acute respiratory syndrome coronavirus-2 (SARS-CoV-2) infection has rapidly spread across the world since its first emergence in China in late 2019. It is a major public health concern with no effective treatct 3 ments. The immunopathology of SARS-CoV2 is associated with an excessive inflammatory response. Macrophage activation syndrome (MAS) is also associated with the severity of the disease in SARS-CoV-2-infected patients. Neopterin is a macrophage activation marker produced by monocytes and macrophages upon activation by interferon-gamma (IFN- $\gamma$ ). Neopterin is a well-established marker in a variety of diseases, and recent evidence indicates that it could be helpful in early prediction of the severity of COVID-19 disease and serve as a prognostic marker. Here, we outline the role of macrophage activation syndrome in the pathogenesis of SARS-CoV-2 and suggest that neopterin could be used as a biomarker for progression of COVID-19.
\end{abstract}

Keywords: neopterin, biomarker, MAS, SARS-CoV-2, COVID-19

\section{Introduction}

Since the first report in Wuhan, China on December 30, 2019, coronavirus disease 2019 (COVID-19) has evolved into a global pandemic. As of December 11, 2020, more than 69.5 million COVID-19 cases have been confirmed as well as more than 1.5 million deaths. ${ }^{1}$ It is now known that COVID-19 is caused by infection with severe acute respiratory syndrome corona virus 2 (SARS-CoV-2). The clinical course of SARSCoV-2 infection appears to be wide-ranging, involving asymptomatic infection, mild upper respiratory tract illness to severe respiratory distress syndrome, and death. ${ }^{2}$ Furthermore, a study has also shown that the highest risk of disease severity and death is in people aged 60 and above and those with prior co-morbidities, including cancer, diabetes, and hypertension. ${ }^{3}$ The disease is relatively mild in pediatrics, since children had shown better prognosis, and deaths were extremely rare. ${ }^{4}$

It is now evident that hyper-inflammatory syndrome is a major cause of disease severity and death in SARS-CoV-2 infected patients. This includes higher production of cytokines, such as IFN- $\gamma$ and IL-6. Extensive cellular infiltration, mostly by macrophages, has been found in post-mortem lungs of SARS-CoV-2 patients. ${ }^{5}$ Recent understanding of the immunopathology of COVID-19 indicates that there is uncontrolled monocyte and macrophage activation, which is largely mediated by IFN- $\gamma$ in response to SARS-CoV-2. This situation has been shown to play a key role in subsequent inflammatory response and organ injury. ${ }^{6}$

The elevated levels of inflammatory markers, including C-reactive protein, ferritin, D-dimer, inflammatory cytokines, and chemokines, and increased neutrophil to 
lymphocyte ratio have been linked with disease severity and death in COVID-19. ${ }^{5}$ The discovery of how different biomarkers behave during the course of the disease could help clinicians in unraveling information about its progression. Hence, clinical symptoms could be interpreted more confidently with the use of such biomarkers and patients could be categorized into mild, severe or critical conditions. ${ }^{7}$

Neopterin has been utilized as a marker for early assessment of disease severity in a variety of diseases. ${ }^{8-11}$ It was first discovered in pigments of bee larvaeand was later recognized as a marker of macrophage activation primarily released by activated monocytes and macrophages. The main trigger for neopterin production is the pro-inflammatory cytokine IFN- $\gamma$, released from activated $\mathrm{T}$ cells. ${ }^{12}$ Macrophage activation syndrome (MAS) has also been shown to be associated with disease severity in patients with SARS-CoV-2. ${ }^{5}$ Therefore, targeting of neopterin in SARS-CoV-2 infection may be critical in the early prediction of disease progression and provision of timely management of infected individuals. Although the level of serum neopterin has been measured to assess the immune activation in several diseases, few studies have been done among individuals infected with SARS-CoV-2. Therefore, this review was intended to describe the significance of neopterin as a diagnostic and prognostic marker in COVID-19 patients.

\section{Biosynthesis of Neopterin}

Neopterin belongs to a group of pteridine compounds containing 2-amino, 4-oxo, pyrimidino-pyrazino (pteridine ring), with a 3-carbon side-chain on carbon- $6 .{ }^{13}$ Neopterin is biosynthetically derived from guanosine triphosphate (GTP) as shown in Figure 1. The GTP cyclohydrolase-I (GTP-CH-I) first cleaves GTP to synthesize 7, 8-dihydroneopterin triphosphate (NH2TP). This intermediate is then converted by 6-pyruvoyl-tetrahydropterin synthase (PTPS) yielding dihydrobiopterin in the biosynthetic pathway of 5.6.7.8-tetrahydrobiopetrin. Since humans and primates are the only species with a deficiency of PTPS enzyme, the NH2TP accumulates in the form of neopterin. ${ }^{14,15}$

Neopterin is mainly produced by human monocytes and macrophages and its potent stimulus is IFN- $\gamma$, through the activation of GTP cyclohydrolase-I. ${ }^{16}$ It is also produced by monocytic derived dendritic cells, and its production rises upon stimulation with IFN- $\gamma .{ }^{17}$ In distinction from monocytes and macrophages, neopterin production is highly sensitive to IFN- $\alpha$ and IFN- $\beta$ in dendritic cells. LPS is also an effective inducer of neopterin release in dendritic cells. ${ }^{17,18}$
After stimulation dendritic cells degrade tryptophan via the tryptophan kynurenine pathway, $\mathrm{N}$-formyl kynurenine is the first intermediate formed in response to indoleamine $(2,3)$ dioxygenase enzyme (IDO).${ }^{19}$ It has been shown that kynurenine could play a physiological role by suppressing the immune functions of T cells and NK-cells. IDO is produced by vascular endothelial cells and activated via IFN- $\gamma$ released by dendritic cells and T cells. ${ }^{20,21}$ IDO regulates the tryptophan kynurenine pathway by degradation of tryptophan. Neopterin formation is related to tryptophan catabolism, considering that both are stimulated by IFN- $\gamma^{22,23}$ Thus, the accumulation of neopterin and reduction of tryptophan could reflect IFN- $\gamma$ induced macrophage activation. As IFN- $\gamma$ is primarily produced by $\mathrm{T}$ helper 1 cells (Th1) after activation, the accretion of neopterin can be an indicator of systemic immune activation, particularly cellmediated immunity (Figure 1).

Neopterin may also be used as a marker of oxidative stress. It has been shown that GTP-CH is inhibited during oxidative stress and results in significant inhibition of neopterin biosynthesis. ${ }^{24}$ Elevated serum neopterin plays a major role in modulation of reactive oxygen substance (ROS) mediated processes by modulating intracellular signal transduction cascade and activates the ROS sensitive transcription factor nuclear factor $\kappa \mathrm{B}(\mathrm{NF}-\kappa \mathrm{B})$. NF- $\kappa \mathrm{B}$ induces pro-inflammatory genes such as inducible nitric oxide synthase (iNOS) and cyclooxygenase-2 (COX-20)

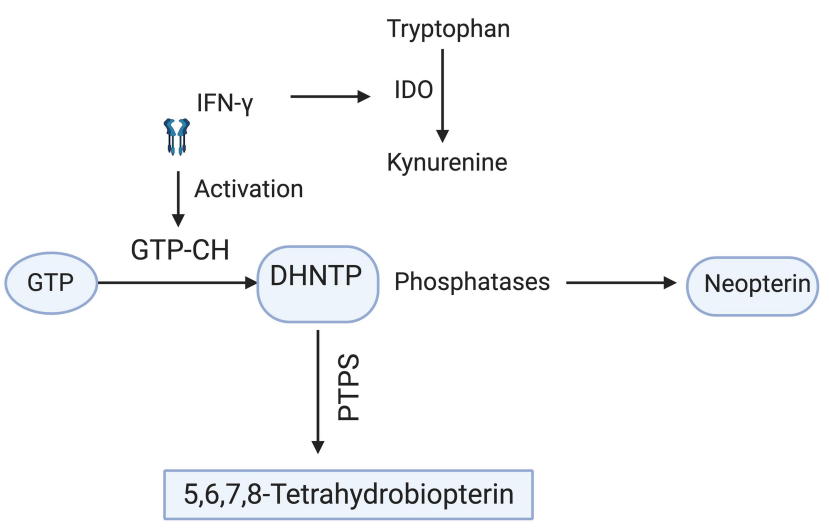

Figure I Biosynthesis of neopterin: IFN- $\gamma$ activates GTP cyclo-hydrolase that further cleaves GTP to 7, 8-dihydro-neopterin triphosphate and phosphatases in turn change this intermediate to neopterin. Since humans lack PTPS, an enzyme which converts DHNTP into 5.6.7.8-tetra hydrobiopetrin, the DHNTP is only biosynthesized to neopterin. On the other hand IFN- $\gamma$ initiates tryptophan degradation to kynurenine by activating IDO enzyme. Thus, there is a direct correlation between increased neopterin and tryptophan degradation. The figure is created with https://app.biorender.com.

Abbreviations: IDO, indoleamine $(2,3)$ deoxygenase; IFN- $\gamma$, interferon gamma; GTP, guanosine triphosphate; GTP-CH, guanosine triphosphate cyclo-hydrolase; DHNTP, 7, 8-dihydro-neopterin-triphosphate; PTPS, 6-pyruvoyl-tetrahydropterin synthase. 
and further enhances inflammatory processes. $^{25,26}$ Neopterin derivatives have been shown to induce programmed cell death which is mediated by reactive oxygen intermediates. Neopterin stimulates iNOS gene expression at the mRNA level and subsequent nitric oxide (NO) production which facilitates cytotoxic capability of immune cells. ${ }^{27}$

\section{Clinical Utility of Neopterin}

Neopterin is one of the biochemical markers used to assess the intensity of the cell-mediated immune response. The increased concentration of serum neopterin above the cutoff value of $\leq 10 \mathrm{nmol} / \mathrm{l}$ is observed in irregular conditions with the involvement of cell-mediated immune response. ${ }^{28}$ Considering its significance, stability and simplicity of measurement in various body fluids, currently neopterin utility is rising more widely in clinical practice. ${ }^{29}$

Neopterin is associated with activity of monocytes and macrophages and is released into body fluids such as serum, cerebrospinal fluid, synovial fluid, pancreatic juice, urine, saliva and ascites fluid. Neopterin concentration reflects level of oxidative stress caused by immune activation since its production is correlated to cells' hydrogen peroxide $\left(\mathrm{H}_{2} \mathrm{O}_{2}\right)$ release. ${ }^{30}$ Neopterin measurements not only provide an insight into the state of the cellmediated immune response but also allow monitoring and prognosis of disease progression. The level of neopterin is elevated in infections, autoimmune diseases, malignancies, allograft rejection, cardiac and renal failure, coronary artery disease and myocardial infarction. ${ }^{27}$

Elevated levels of serum neopterin have been observed in the early stages of various viral infections. These include dengue, hepatitis B, Ebola, and influenza viruses. ${ }^{31-34}$ In the case of HIV, on top of CD4 and viral load, it has shown to be linked with the progression of HIV infection and identified as a prognostic marker. ${ }^{35,36}$ In addition to being a marker of viral infection, neopterin has a wide range of applications in bacterial and parasitic infectious diseases, cardiovascular diseases, and cancer. ${ }^{37-40}$

\section{COVID-I 9 and Macrophage Activation Syndrome}

The immune response to SARS-CoV-2 is usually hyperactive in symptomatic patients. Particularly, in patients with acute respiratory distress syndrome (ARDS), this is characterized by an excessive inflammatory response in the lung. This is largely mediated by the release of a high level of pro- inflammatory cytokines, such as IL-6, TNF- $\alpha$, and IL-1, together with an increase in expression of cell adhesion molecules. ${ }^{41}$ Subsequently, the recruitment of neutrophils and inflammatory monocytes to the lung is uplifted. ${ }^{42}$

Similar to SARS-CoV and Middle East respiratory syndrome coronavirus (MERS-CoV), SARS-CoV-2 has been shown to infect alveolar macrophages, through angiotensin converting enzyme-2 (ACE2). Antibodydependent enhancement (ADE) has also been revealed to facilitate the infection of macrophages via FcR. In patients with critical stages of acute respiratory distress syndrome (ARDS), a massive infiltration and activation of alveolar macrophages were evident. ${ }^{43}$ Although the viral replication is still not observed, macrophages produce an extensive amount of inflammatory mediators that support COVID-19 related local tissue inflammation and systemic inflammatory response. ${ }^{44} \mathrm{MAS}$ is defined as a state of hyper-inflammation with the up-regulated expression of pro-inflammatory cytokines, including TNF- $\alpha$, IL-6, and IL-1 upon stimulation. The extraordinary aggregation and activation of these macrophages and their byproducts could contribute to the detrimental form of inflammatory response, the most frequently reported COVID-19 associated pathogenesis.

Furthermore, the continuous monocyte-macrophage activation may lead to respiratory failure in severely affected patients with SARS-CoV-2. ${ }^{45}$ Besides this, MAS associated life-threatening complications have been reported in several auto-immune diseases. These are related to hemophagocytic lymphocytosis (HLH), by which uncontrolled proliferation of the well-differentiated macrophages leads to widespread hemophagocytosis and cytokine production. ${ }^{46,47}$ Taken together, as a macrophage activation marker, neopterin could be a promising biomarker for the MAS immunopathology of COVID-19. ${ }^{48}$ The lower right part of Figure 2 shows how MAS occurs in COVID-19 and the resulting release of neopterin from macrophages induced by IFN- $\gamma$ (Figure 2).

\section{Neopterin in COVID-1 9 Patients}

Inflammatory diseases are often accompanied by the activation of monocytes and macrophages. Neopterin, one of the products of these cells, has been widely studied as a possible marker for diseases, such as viral infection, malignant disease, and autoimmune diseases including inflammatory bowel disease. In these illnesses, neopterin has been shown to be linked with disease severity. ${ }^{49}$ Regarding COVID-19, a stockpile of evidence signifies that inflammatory responses 


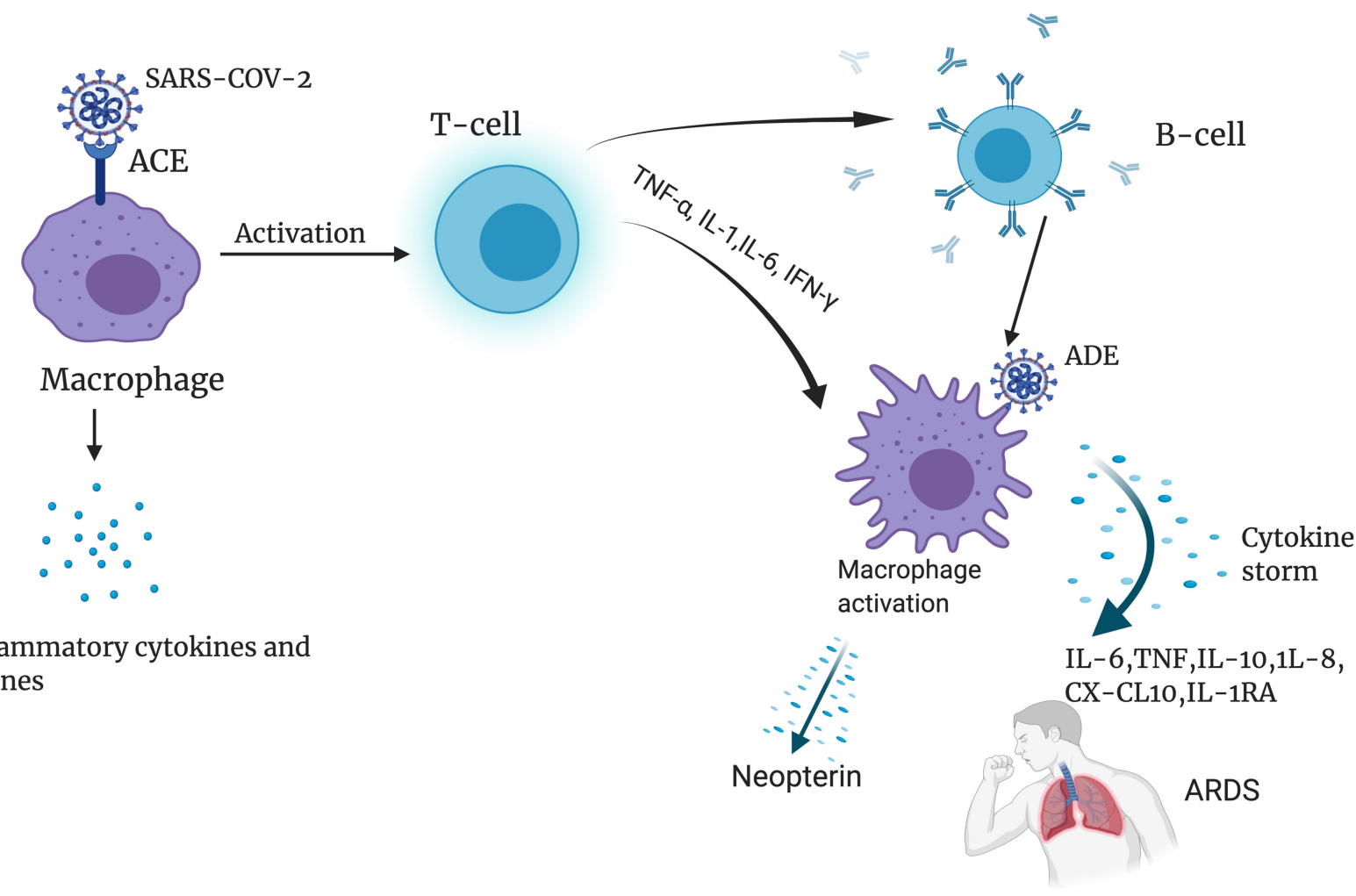

Figure 2 The relationship between MAS, neopterin, and COVID-19 pathogenesis: The SARS-CoV-2 spike protein binds to ACE, on the surface of macrophages (in the top left corner). Macrophages then release pro-inflammatory cytokines and chemokines to infiltrating immune cells and ignite the inflammation. As shown in the top right corner, T cells followed by B cells are activated, release of SARS-CoV-2 specific antibodies facilitates the entry of the virus into monocytes and macrophages via FcR. Macrophages are also activated by the T cell-derived cytokine IFN- $\gamma$, leading to the release of a high number of cytokines resulting in a cytokine storm and eventually ARDS (in the lower right corner). Meanwhile, neopterin production is stimulated in activated macrophages with cytokines, mainly IFN- $\gamma$ from T cells. The figure is created with https://app. biorender.com.

Abbreviations: ACE, angiotensin-converting enzyme; ADE, antibody-dependent enhancement; ARDS, acute respiratory distress syndrome; IL-6, interleukin-6; IL-8, interleukin-8; TNF, tumor necrosis factor; CX-CL-10, chemokine ligand 10.

play a critical role in disease progression. The inflammatory response prompted by rapid SARS-CoV-2 replication and cellular destruction recruits monocytes and macrophages, resulting in the release of cytokines and chemokines, which in turn results in immunological chaos. ${ }^{50,51}$

A recent meta-analysis and review showed that inflammatory markers are positively correlated with severity of COVID-19. It recommended measurement of C-reactive protein (CRP), procalcitonin, IL-6 and erythrocyte sedimentation rate (ESR) might help clinicians to evaluate severity and prognosis of COVID-19. ${ }^{52,53}$ Although neopterin was not included in these studies, it is a well-established and reliable inflammatory marker that could give similar and even much better benefit. ${ }^{54}$

According to a recent study, neopterin has been shown to increase in acute stages of viral infections. In addition to its increment in the acute stages, neopterin has been shown to appear before the onset of clinical symptoms. ${ }^{55}$ In the 2002 SARS outbreak, a study reported that serum neopterin levels were raised in SARS patients on the day of symptom onset. ${ }^{56}$ Furthermore, the neopterin level was also determined along with CRP, the most common acute phase reactant that indicates inflammation. In patients with acute SARS infection, the level of neopterin was shown to be five times higher than in recovered individuals and four-fold higher compared with healthy controls. However, CRP concentration did not show any significant difference between the groups. Elevated neopterin concentration in SARS patients was associated with a longer fever period and thus a more severe course of the disease. ${ }^{56}$ Given SARS-CoV-2 infection is closely related to previous SARS in several aspects, it might be beneficial for monitoring patients in the current COVID-19 pandemic. ${ }^{55}$

Even though COVID-19 is associated with activation of the inflammatory response, only a few studies have assessed the level of neopterin in COVID-19 patients. A recent study found a two-fold higher mean concentration of neopterin in severely ill patients compared with patients with mild 
Table I Neopterin Levels of COVID-19 Patients

\begin{tabular}{|c|c|c|c|c|c|c|c|c|}
\hline Year & Study & Country & $\mathbf{N}$ & Sample & $\begin{array}{l}\text { Neopterin } \\
\text { (COVID-19) }\end{array}$ & $\begin{array}{l}\text { Neopterin (Severe } \\
\text { COVID-19) }\end{array}$ & $\begin{array}{l}\text { Neopterin (Mild } \\
\text { COVID-19) }\end{array}$ & $\begin{array}{l}\text { Neopterin } \\
\text { Healthy Controls }\end{array}$ \\
\hline 2020 & Ozger etal ${ }^{58}$ & Turkey & 134 & Serum & $46 \mathrm{nmol} / /^{\mathrm{a}} \mathrm{med}$ & NA & NA & $12 \mathrm{nmol} / /^{\mathrm{a}}$ \\
\hline 2020 & Roberstson et $\mathrm{al}^{57}$ & Sweden & 34 & Serum & NA & $42 \mathrm{nmol} / /^{b}$ & $16.9 \mathrm{nmol} / /^{\mathrm{b}}$ & NA \\
\hline 2020 & $\begin{array}{l}\text { Bellmann- } \\
\text { Weiler et al }\end{array}$ & Austria & 115 & Serum & NA & $56.6 \mathrm{nmol} / \mathrm{l}$ & $34.7 \mathrm{nmol} / \mathrm{I}$ & NA \\
\hline \multirow[t]{2}{*}{2020} & Magnus et $\mathrm{al}^{59}$ & Sweden & 6 & CSF & NA & $43 \mathrm{nmol} / /^{\mathrm{a}}$ & NA & NA \\
\hline & & & & Serum & NA & $41.9 \mathrm{nmol} / \mathrm{l}^{\mathrm{a}}$ & NA & NA \\
\hline
\end{tabular}

Notes: a Median; ${ }^{\mathrm{b}}$ Mean; Neopterin reference range (serum $\leq 10 \mathrm{nmol} / \mathrm{l}, \mathrm{CSF} \leq 6 \mathrm{nmol} / \mathrm{l}$ ).

Abbreviations: NA, not applicable; N, sample size; COVID-19, coronavirus disease 2019

symptoms. The level of neopterin was gradually decreasing in both mild and severely ill patients, however, severe cases maintained the elevated levels for a longer time. ${ }^{57}$ Likewise, a similar report showed that patients with severe COVID-19 had higher levels compared with mild cases on hospital admission and a four-fold increase compared with healthy controls. ${ }^{58}$

CSF inflammatory biomarkers including neopterin were assessed in COVID-19 patients with neurological signs and symptoms by Magnus et al. In line with the above observations CSF and serum neopterin concentrations were elevated in all patients. This outlines that marked elevation of inflammatory biomarkers such as neopterin may be associated with neurological manifestations in COVID-19. The profound CNS immune activation reflected by high CSF neopterin may be driven by an intense systemic inflammatory response induced by SARS-CoV-2 infection. The pathophysiological bases of markedly elevated CSF neopterin in SARS-CoV-2 infection remain uncertain and need to be explored. ${ }^{59}$

Neopterin level has been shown to be positively correlated with parameters determined for COVID-19 patients such as IL-6, CRP, and PCT. It is also further correlated with oxygen saturation and requirement. Regarding predictive potential, patients with neopterin level $>45 \mathrm{nmol} / 1$ upon admission had four times higher risk for death, 14 times higher rates of ICU admission and 16- fold need of mechanical ventilation during hospital stay compared with patients with neopterin $\leq$ $45 \mathrm{nmol} / 1 .{ }^{60}$ All current studies have observed elevated neopterin in COVID-19 patients, particularly severely ill patients. Table 1 summarizes study reports of neopterin levels in COVID-19 patients. Based on the above-mentioned evidence neopterin may allow early identification of patients at risk of needing mechanical ventilation and ICU treatment. These pieces of evidence indicate that neopterin can serve as a prognostic marker for following progression of COVID-19 (Table 1).

\section{Conclusion}

MAS, which results in systemic inflammation and ARDS, are a major pathology of COVID-19. Confirming experience with SARS, recent reports in SARS-CoV-2 patients showed an elevated level of neopterin concentration in severe COVID-19 compared with mild cases. The level of neopterin gradually decreases with the clinical course of COVID-19 in mild cases; however, it is consistently prominent in severe cases. Thus, neopterin could be used as a biomarker for the prediction of COVID-19 disease severity. This has an implication in early diagnosis and monitoring of the illness and could prevent unprecedented loss of lives. Although few studies have shown the increment of neopterin in COVID-19 patients, it has to be noted that further larger studies are needed to be conducted.

\section{Author Contributions}

All authors made a significant contribution to the work reported, whether that is in the conception, study design, execution, acquisition of data, analysis, and interpretation, or in all these areas; took part in drafting, revising, or critically reviewing the article; gave final approval of the version to be published; have agreed on the journal to which the article has been submitted; and agree to be accountable for all aspects of the work.

\section{Funding}

The authors received no specific fund for this work.

\section{Disclosure}

The authors report no potential conflicts of interest for this work.

\section{References}

1. JHU. Corona virus resource center. JHU; 2020. Available from: https:// coronavirus.jhu.edu/. Accessed December 11, 2020. 
2. Zhou F, Yu T, Du R, et al. Clinical course and risk factors for mortality of adult inpatients with COVID-19 in Wuhan, China: a retrospective cohort study. Lancet. 2020.

3. Guan WJ, Ni ZY, Hu Y, et al. Clinical characteristics of coronavirus disease 2019 in China. N Engl J Med. 2020;382(18):1708-1720. doi:10.1056/NEJMoa2002032

4. Ludvigsson JF. Systematic review of COVID-19 in children shows milder cases and a better prognosis than adults. Acta Paediatrica. 2020;109(6):1088-1095. doi:10.1111/apa.15270

5. Merad M, Martin JC. Pathological inflammation in patients with COVID-19: a key role for monocytes and macrophages. Nat Rev Immunol. 2020:1-8.

6. Webb BJ, Peltan ID, Jensen P, et al. Clinical criteria for COVID-19associated hyperinflammatory syndrome: a cohort study. Lancet Rheumatol. 2020;2(12):e754-e763. doi:10.1016/S2665-9913(20) 30343-X

7. Kermali M, Khalsa RK, Pillai K, Ismail Z, Harky A. The role of biomarkers in diagnosis of COVID-19-A systematic review. Life Sci. 2020:117788.

8. Eisenhut M. Neopterin in diagnosis and monitoring of infectious diseases. J biomark. 2013;2013:1-10.

9. Fuchs D, Avanzas P, Arroyo-Espliguero R, Jenny M, ConsuegraSanchez L, Kaski J. The role of neopterin in atherogenesis and cardiovascular risk assessment. Curr Med Chem. 2009;16 (35):4644-4653. doi:10.2174/092986709789878247

10. Murr C, Fuith L, Widner B, Wirleitner B, Baier-Bitterlich G, Fuchs D. Increased neopterin concentrations in patients with cancer: indicator of oxidative stress? Anticancer Res. 1999;19(3A): 1721-1728.

11. Yadav AK, Sharma V, Jha V. Association between serum neopterin and inflammatory activation in chronic kidney disease. Mediators Inflamm. 2012;2012. doi:10.1155/2012/476979

12. Hoffmann G, Wirleitner B, Fuchs D. Potential role of immune system activation-associated production of neopterin derivatives in humans. Inflamm Res. 2003;52(8):313-321. doi:10.1007/s000 11-003-1181-9

13. Müller MM, Curtius H-C, Herold M, Huber CH. Neopterin in clinical practice. Clinica chimica acta. 1991;201(1-2):1-16.

14. Murr C, Widner B, Wirleitner B, Fuchs D. Neopterin as a marker for immune system activation. Current Drug Metabolism. 2002;3 (2):175-187. doi:10.2174/1389200024605082

15. Fuchs D, Weiss G, Wachter H. Neopterin, biochemistry and clinical use as a marker for cellular immune reactions. Int Arch Allergy Immunol. 1993;101(1):1-6. doi:10.1159/000236491

16. Huber C, Batchelor JR, Fuchs D, et al. Immune response-associated production of neopterin. Release from macrophages primarily under control of interferon-gamma. J Exp Med. 1984;160(1):310-316. doi:10.1084/jem.160.1.310

17. Wirleitner B, Reider D, Ebner S, et al. Monocyte-derived dendritic cells release neopterin. J Leukocyte Biol. 2002;72(6):1148-1153.

18. Sghiri R, Feinberg J, Thabet F, et al. Gamma interferon is dispensable for neopterin production in vivo. Clin Diagn Lab Immunol. 2005;12 (12):1437-1441. doi:10.1128/CDLI.12.12.1437-1441.2005

19. Werner-Felmayer G, Werner ER, Fuchs D, Hausen A, Reibnegger G, Wachter H. Characteristics of interferon induced tryptophan metabolism in human cells in vitro. Biochimica et Biophysica Acta. 1989;1012(2):140-147. doi:10.1016/0167-4889(89)90087-6

20. Terness P, Bauer TM, Rose L, et al. Inhibition of allogeneic T cell proliferation by indoleamine 2, 3-dioxygenase-expressing dendritic cells: mediation of suppression by tryptophan metabolites. $J$ Exp Med. 2002;196(4):447-457. doi:10.1084/jem.20020052

21. Hol JW, Stolker RJ, Klimek M, Stronks DL, Fekkes D. The tryptophan kynurenine pathway, neopterin and IL-6 during vulvectomy and abdominal hysterectomy. J Biomed Sci. 2014;21(1):102. doi:10.1186/ s12929-014-0102-2
22. Widner B, Leblhuber F, Fuchs D. Increased neopterin production and tryptophan degradation in advanced Parkinson's disease. J Neural Transm. 2002;109(2):181-189. doi:10.1007/s007020200014

23. Fuchs D, Möller AA, Reibnegger G, et al. Increased endogenous interferon-gamma and neopterin correlate with increased degradation of tryptophan in human immunodeficiency virus type 1 infection. Immunol Letters. 1991;28(3):207-211. doi:10.1016/0165-2478(91) 90005-u

24. Svoboda P, Ko S-H, Cho B, et al. Neopterin, a marker of immune response, and 8-hydroxy-2'-deoxyguanosine, a marker of oxidative stress, correlate at high age as determined by automated simultaneous high-performance liquid chromatography analysis of human urine. Anal Biochem. 2008;383(2):236-242. doi:10.1016/j.ab.2008.09.014

25. Toygar M, Aydin I, Agilli M, et al. The relation between oxidative stress, inflammation, and neopterin in the paraquat-induced lung toxicity. Hum Exp Toxicol. 2014;34(2):198-204. doi:10.1177/ 0960327114533808

26. Schobersberger W, Hoffmann G, Grote J, Wachter H, Fuchs D. Induction of inducible nitric oxide synthase expression by neopterin in vascular smooth muscle cells. FEBS Lett. 1995;377(3):461-464.

27. Berdowska A, Zwirska-Korczala K. Neopterin measurement in clinical diagnosis. J Clin Pharm Ther. 2001;26(5):319-329. doi:10.1046/ j.1365-2710.2001.00358.x

28. Plata-Nazar K, Jankowska A. Clinical usefulness of determining the concentration of neopterin. Pteridines. 2011;22(1):77. doi:10.1515/ pteridines.2011.22.1.77

29. Müller MM, Curtius H-C, Herold M, Huber CH. Neopterin in clinical practice. Clinica Chimica Acta. 1991;201(1):1-16.

30. Firth CA, Laing AD, Baird SK, Pearson J, Gieseg SP. Inflammatory sites as a source of plasma neopterin: measurement of high levels of neopterin and markers of oxidative stress in pus drained from human abscesses. Clin Biochem. 2008;41(13):1078-1083. doi:10.1016/j. clinbiochem.2008.06.008

31. Chan CPY, Choi JWY, Cao K-Y, et al. Detection of serum neopterin for early assessment of dengue virus infection. J Infect. 2006;53 (3):152-158. doi:10.1016/j.jinf.2005.11.008

32. Kalkan A, Ozden M, Akbulut H. Serum neopterin levels in patients with chronic hepatitis B. Jpn J Infect Dis. 2005;58(2):107-109.

33. Pizzini A, Kurz K, Santifaller J, et al. Assessment of neopterin and indoleamine 2,3-dioxygenase activity in patients with seasonal influenza: a pilot study. Influenza Other Respir Viruses. 2019;13(6):603609. doi:10.1111/irv.12677

34. Onguru P, Akgul EO, Akıncı E, et al. High serum levels of neopterin in patients with Crimean-Congo hemorrhagic fever and its relation with mortality. $J$ Infect. 2008;56(5):366-370. doi:10.1016/j.jinf.20 08.03.006

35. Mildvan D, Spritzler J, Grossberg SE, et al. Serum neopterin, an immune activation marker, independently predicts disease progression in advanced HIV-1 infection. Clin Infect Dis. 2005;40(6):853858. doi:10.1086/427877

36. Wirleitner B, Schroecksnadel K, Winkler C, Fuchs D. Neopterin in HIV-1 infection. Mol Immunol. 2005;42(2):183-194. doi:10.1016/j. molimm.2004.06.017

37. Eisenhut M. Neopterin in diagnosis and monitoring of infectious diseases. J Biomark. 2013;2013:196432.

38. Pacileo M, Cirillo P, De Rosa S, et al. The role of neopterin in cardiovascular disease. Monaldi Arch Chest Dis. 2007;68(2):68-73. doi:10.4081/monaldi.2007.454

39. Sucher R, Schroecksnadel K, Weiss G, Margreiter R, Fuchs D, Brandacher G. Neopterin, a prognostic marker in human malignancies. Cancer Lett. 2010;287(1):13-22. doi:10.1016/j.canlet.2009.05. 008

40. Melichar B, Spisarová M, Bartoušková M, Krčmová LK, Javorská L, Študentová H. Neopterin as a biomarker of immune response in cancer patients. Ann Transl Med. 2017;5(13):280. doi:10.21037/ atm.2017.06.29 
41. Braciale TJ, Hahn YS. Immunity to viruses. Immunol Rev. 2013;255 (1):5-12. doi:10.1111/imr.12109

42. Ragab D, Salah Eldin H, Taeimah M, Khattab R, Salem R. The COVID-19 cytokine storm; what we know so far. Front Immunol. 2020;11:1446. doi:10.3389/fimmu.2020.01446

43. Wang C, Xie J, Zhao L, et al. Aveolar macrophage activation and cytokine storm in the pathogenesis of severe COVID-19. Research Square; 2020.

44. Jafarzadeh A, Chauhan P, Saha B, Jafarzadeh S, Nemati M. Contribution of monocytes and macrophages to the local tissue inflammation and cytokine storm in COVID-19: lessons from SARS and MERS, and potential therapeutic interventions. Life Sci. 2020:118102.

45. Gómez-Rial J, Rivero-Calle I, Salas A, Martinón-Torres FJI. Role of monocytes/macrophages in covid-19 pathogenesis: implications for therapy. Infect Drug Resist. 2020;13:2485. doi:10.2147/IDR.S258639

46. Ravelli A. Macrophage activation syndrome. Curr Opinion Rheumatol. 2002;14(5):548-552. doi:10.1097/00002281-20020900000012

47. Lerkvaleekul B, Vilaiyuk S. Macrophage activation syndrome: early diagnosis is key. Open Access Rheumatol: Res Rev. 2018;10:117. doi:10.2147/OARRR.S151013

48. McGonagle D, Sharif K, O'Regan A, Bridgewood C. The role of cytokines including interleukin-6 in COVID-19 induced pneumonia and macrophage activation syndrome-like disease. Autoimmun Rev. 2020;19(6):102537. doi:10.1016/j.autrev.2020.102537

49. Forrest CM, Youd P, Kennedy A, Gould SR, Darlington LG, Stone TW. Purine, kynurenine, neopterin and lipid peroxidation levels in inflammatory bowel disease. J Biomed Sci. 2002;9(5):436-442. doi:10.1007/BF02256538
50. Carvelli J, Demaria O, Vély F, et al. Association of COVID-19 inflammation with activation of the $\mathrm{C} 5 \mathrm{a}-\mathrm{C} 5 \mathrm{aR} 1$ axis. Nature. 2020:1-5.

51. Tay MZ, Poh CM, Rénia L, MacAry PA, Ng LF. The trinity of COVID-19: immunity, inflammation and intervention. Nat Rev. 2020:1-12.

52. Feng X, Li S, Sun Q, et al. Immune-inflammatory parameters in COVID-19 cases: a systematic review and meta-analysis. Front Med. 2020;7(301).

53. Zeng F, Huang Y, Guo Y, et al. Association of inflammatory markers with the severity of COVID-19: a meta-analysis. Int $J$ Infect Dis. 2020.

54. Senanayake SL Drug repurposing strategies for COVID-19. Future Science; 2020.

55. Park M, Thwaites RS, Openshaw PJ. COVID-19: lessons from SARS and MERS. Eur J Immunol. 2020;50(3):308.

56. Zheng B, Cao K-Y, Chan CP, et al. Serum neopterin for early assessment of severity of severe acute respiratory syndrome. Clin Immunol. 2005;116(1):18-26. doi:10.1016/j.clim.2005.03.009

57. Robertson J, Gostner JM, Nilsson S, Andersson L-M, Fuchs D, Gisslen M. Serum neopterin levels in relation to mild and severe COVID-19. medRxiv. 2020. doi:10.1101/2020.08.13.20147595

58. Ozger HS, Dizbay M, Corbacioglu SK, et al. The prognostic role of neopterin in COVID-19 patients. J Med Virol. 2020.

59. Edén A, Kanberg N, Gostner J, et al. CSF biomarkers in patients with COVID-19 and neurological symptoms: a case series. Neurology. 2020. doi:10.1212/WNL.0000000000010977

60. Bellmann-Weiler R, Lanser L, Burkert F, et al. Neopterin predicts disease severity in hospitalized patients with COVID-19. Open Forum Infect Dis. 2020. doi:10.1093/ofid/ofaa521
Journal of Inflammation Research

\section{Publish your work in this journal}

The Journal of Inflammation Research is an international, peerreviewed open-access journal that welcomes laboratory and clinical findings on the molecular basis, cell biology and pharmacology of inflammation including original research, reviews, symposium reports, hypothesis formation and commentaries on: acute/chronic inflammation; mediators of inflammation; cellular processes; molecular mechanisms; pharmacology and novel anti-inflammatory drugs; clinical conditions involving inflammation. The manuscript management system is completely online and includes a very quick and fair peerreview system. Visit http://www.dovepress.com/testimonials.php to read real quotes from published authors. 